\title{
EFEITO DE ÓLEO VEGETAL DE ALGODÃO NO CONTROLE DE Zabrotes subfasciatus (Coleoptera: Bruchidae) EM SEMENTES DE FEIJÃO.
}

\author{
Marina Funichello ${ }^{1}$, Luana Godoi Santos ${ }^{2}$ \\ ${ }^{1}$ Faculdade de Tecnologia de Presidente Prudente - FATEC. ${ }^{2}$ Faculdades Gammon, curso de Agronomia, Paraguaçu \\ Paulista, SP. E-mail: mfunichello@gmail.com
}

\section{RESUMO}

O presente trabalho teve como objetivo, avaliar o efeito do óleo de algodão no controle de $Z$. subfasciatus em diferentes sementes de feijoeiro. Para a realização do experimento, foram utilizados as cultivares de feijão: Campos Gerais, Gol 600 e Estilo, onde todas foram submetidas ao tratamento com óleo contendo uma testemunha de cada cultivar. Foram utilizadas placas de Petri com $250 \mathrm{~g}$ de sementes e acondicionados 3 casais de $Z$. subfasciatus. Os parâmetros avaliados foram: número de ovos, número de emergência de adultos, mortalidade dos insetos, vigor e germinação das sementes. Os tratamentos com óleo vegetal de algodão demonstraram ser eficientes na redução da oviposição e da emergência de adultos do caruncho. O óleo não afetou na qualidade fisiológica da semente relativa à porcentagem de vigor e germinação nas cultivares testadas.

Palavras-chave: caruncho, plantas inseticidas, pragas de grãos armazenados, manejo integrado de pragas, germinação.

\section{EFFECT OF COTTON OIL IN THE Zabrotes subfasciatus (COLEOPTERA:BRUCHIDAE) CONTROL IN BEAN SEEDS.}

\begin{abstract}
The objective of this work was to evaluate the effect of cotton oil on the control of Z. subfasciatus in different bean seeds. For the experiment, three cultivars of beans: Campos Gerais, Gol 600 and Estilo were used, where all cultivars were submitted to treatment with oil containing one control of each cultivar. Petri dishes containing $250 \mathrm{~g}$ of seeds and 3 couples of the species $Z$. subfasciatus were used. The parameters evaluated were: number of eggs, adult emergence number, insect mortality, vigor, and seed germination. The treatments with cotton vegetal oil proved to be efficient in reducing the oviposition and the emergence of adults of the insect. In addition, the oil did not affect the physiological quality of the seed relative to the percentage of vigor and germination in the tested cultivars.
\end{abstract}

Keywords: insect, pesticide plants, Integrated pest management.

\section{INTRODUÇÃO}

O feijoeiro-comum (Phaseolus vulgaris, L.) é uma das principais culturas cultivadas no Brasil e no mundo, sua importância extrapola o aspecto econômico, por sua relevância enquanto fator de segurança alimentar e nutricional e sua importância cultural na culinária de diversos países e culturas. A cultura do feijão é uma leguminosa usada como fonte de proteína para grande parte da população mundial, especialmente onde o consumo de proteína animal é relativamente escasso (AFONSO, 2010). 
O feijoeiro possui várias pragas de armazenamento, cerca de mais de 20 espécies pertencentes a seis gêneros da família Bruchidae que se desenvolve em sementes de leguminosas que são armazenadas e consumidas pelo homem (SARI et al., 2003). Dentre as pragas de armazenamento no feijão destaca-se o caruncho Zabrotes subfasciatus, este ataca os cotilédones da semente e, na sua fase larval, abre galerias, podendo destruí-las completamente, ao que se soma a presença de ovos nos grãos, de orifícios de emergência dos adultos, de insetos mortos e de excrementos que afetam a qualidade do produto. As sementes destinadas à semeadura têm os embriões destruídos ficando seriamente prejudicados (QUEIROGA et al. 2012), prejudicando diretamente a comercialização deste material.

O uso de produtos químicos é uma tática importante no controle de pragas de grãos armazenados, no entanto, pode causar toxidade e desenvolvimento de populações resistentes de insetos e a presença de resíduos tóxicos segundo Brito et al. (2006), no entanto, o uso de alguns óleos vegetais para o tratamento de sementes tem sido eficiente no controle de carunchos provocando redução na progênie e na emergência de adultos (BRITO et al., 2006).

O óleo de algodão é o sexto mais produzido no mundo, seguido do óleo de palma (dendê) com 35,37 milhões de tonelada, soja com 338 canola com 16,85, girassol com 10.08 e amendoim com 5.17. No Brasil o óleo de algodão possui grande relevância para a agroindústria, sendo o segundo mais produzido com 482 mil toneladas, perdendo apenas para o óleo de soja com 10.230 mil toneladas.

Brito et al. (2006), observaram que o processo de fumigação com óleos essenciais de plantas do gênero Eucalyptus mostrou-se eficiente no controle de Z. subfaciatus e Callosobruchus maculatus. Em trabalho realizado por Arruda e Batista (1998), as sementes de feijão tratadas com óleos vegetais demostraram ser bastante eficientes como ovicidas e/ou larvicida, sendo o óleo de girassol limitante para a emergência do caruncho $C$. maculatus na cultura Sempre Verde.

Desta forma, o presente trabalho visou determinar o efeito do óleo de algodão aplicado em sementes de diferentes cultivares de feijão sobre o controle do caruncho $Z$. subfasciatus.

\section{MATERIAL E MÉTODOS}

O Trabalho foi realizado no laboratório de Entomologia da Faculdades Gammon em temperatura de $25 \pm 5{ }^{\circ} \mathrm{C}$, umidade relativa do ar de $70 \pm 10 \%$ e fotoperíodo de 12 horas.

0 experimento foi realizado em esquema fatorial 3 (cultivares) $\times 2$ (com e sem óleo de algodão), no delineamento experimental inteiramente casualizado, com 10 repetições por tratamento.

As cultivares de feijoeiro utilizadas para o experimento foram: Campos Gerais, Gol 600 e Estilo. As sementes de todas as cultivares foram submetidas ao tratamento com óleo de algodão e sem óleo de algodão.

A dosagem do óleo foi estabelecida na proporção de $300 \mathrm{ml}$ de óleo para cada $100 \mathrm{~kg}$ de semente, segundo metodologia de Arruda e Batista (1998). As sementes foram homogeneizadas com o óleo em erlenmeyer de $500 \mathrm{ml}$, por um período de 2 min e logo após o recipiente foi fechado com algodão.

Após 24 horas, as sementes foram acondicionadas em placas de Petri de $9 \mathrm{~cm}$ de diâmetro. Em cada placa foram colocadas 50 sementes de feijão e 6 carunchos, sendo 3 machos e 3 fêmeas da espécie Z. subfsciatus, fornecidos pelo laboratório de Resistência de Plantas da UNESP de Jaboticabal-SP, com idade variando de 0 a 72 horas. Os insetos foram deixados por 15 dias para a oviposição, e após este período retirados das placas e os ovos foram contados e diariamente as placas foram observadas para a contagem do número de adultos emergidos.

Para a realização do teste de germinação das sementes foram utilizadas quatro folhas de papel germiteste úmido, 2,5 o peso do papel seco, conforme BRASIL (2009).Após este procedimento foram levados para a câmara de germinação por um período de 5 dias com a 
temperatura de $25^{\circ} \mathrm{C}$, depois deste período foram avaliadas as porcentagens de plântulas normais, anormais e sementes mortas.

Conforme BRASIL (2009) para o teste de vigor das sementes, 100 sementes de cada cultivar foram acondicionadas em caixas gerbox com $20 \mathrm{ml}$ de água em cada repetição e conduzido para a estufa de envelhecimento (acelerado), onde a semente passou por um estresse na temperatura de $42^{\circ} \mathrm{C}$ por um período de 48 horas. Após esse período as amostras foram submetidas ao mesmo processo utilizado no teste de germinação diferenciando apenas na quantidade de sementes analisadas.

Devido à baixa germinação das sementes e presença de fungos, foi realizado um teste de patologia em caixa de gerbox e papel (mata borrão) umedecido com agua destilada em teste de patologia de sementes, por 5 dias. Após esse período foi avaliado o desenvolvimento de microrganismo na semente.

Os parâmetros avaliados foram: número de ovos, número de emergência de adultos, mortalidade dos insetos, vigor (envelhecimento acelerado) e germinação. Os dados foram submetidos à análise de variância pelo teste $\mathrm{F}$ e as medias comparadas pelo Teste de Tukey a $5 \%$ de probabilidade.

\section{RESULTADOS}

O número de ovos encontrados nas sementes, em função da postura dos insetos adulto, estão representados na (Tabela 1). A cultivar Gol 600 apresentou maior número de ovos (99), diferindo significativamente da cultivar Campos Gerais, que apresentou uma média de 62 ovos de Z. subfasciatus. No entanto, em relação ao número de insetos adultos emergidos não houve diferença significativa entre as cultivares testadas.

Tabela 1. Número de ovos e insetos emergidos em sementes com e sem o tratamento com óleo de algodão em diferentes cultivares de feijão. Paraguaçu Paulista, 2017.

\begin{tabular}{ccc}
\hline Tratamento & No de ovos & No de insetos \\
\hline Campos Gerais & $62 \mathrm{~b}$ & $52,8 \mathrm{a}$ \\
Gol 600 & $99 \mathrm{a}$ & $59,0 \mathrm{a}$ \\
Estilo & $61,1 \mathrm{ab}$ & $41,5 \mathrm{a}$ \\
\hline F & $3,27^{*}$ & $0,29^{\mathrm{ns}}$ \\
\hline CV (\%) & 26,41 & 46,63 \\
\hline
\end{tabular}

Médias seguidas pela mesma letra não diferem entre si pelo Teste de Tukey a $5 \%$ de probabilidade.

- *: significativo a 5\% probabilidade; ${ }^{\text {ns }}$ : não significativo; CV (\%): coeficiente de variação.

Observa-se na Tabela 2, que o tratamento das cultivares tratadas com óleo apresentaram menor número de ovos dos insetos $(7,3)$, diferindo significativamente dos tratamentos sem a aplicação de óleo, apresentando uma média de 74 ovos. Para o número de insetos emergidos o resultado foi semelhante, os tratamentos com óleo apresentaram menor emergência de insetos adultos.

Tabela 2. Números de ovos e insetos emergidos em diferentes cultivares com e sem óleo de algodão. Paraguaçu Paulista, 2017.

\begin{tabular}{ccc}
\hline Tratamento & № de ovos & № de insetos emergidos \\
\hline Sem óleo & $74 \mathrm{a}$ & $51,2 \mathrm{a}$ \\
Com óleo & $7,3 \mathrm{~b}$ & $4,5 \mathrm{~b}$ \\
\hline $\mathrm{F}$ & $266,79^{* *}$ & $83,37^{* *}$ \\
\hline $\mathrm{CV}(\%)$ & 26,41 & 46,63 \\
\hline
\end{tabular}

Médias seguidas pela mesma letra não diferem entre si pelo Teste de Tukey a $5 \%$ de probabilidade. 
**: significativo a 1\%; CV (\%): Coeficiente de variação.

A Tabela 3, mostra a interação entre as 3 cultivares de feijão testada, tratadas e não tratadas com óleo de algodão. Observa-se que a cultivar Gol 600 sem aplicação do óleo de algodão apresentou maior número de ovos, já entre as cultivares com a aplicação do óleo vegetal, não houve diferença significativa para o número de ovos.

Tabela 3. Desdobramento da interação cultivares com e sem óleo de algodão para o número de ovos. Paraguaçu Paulista, 2017.

\begin{tabular}{ccc}
\hline Cultivares & Sem óleo & Com óleo \\
\hline Campos Gerais & $62 \mathrm{bA}$ & $4 \mathrm{aB}$ \\
Gol 600 & $99 \mathrm{aA}$ & $6,6 \mathrm{aB}$ \\
Estilo & $61,1 \mathrm{bA}$ & $10,5 \mathrm{aB}$ \\
\hline
\end{tabular}

Média seguidas pela mesma letra (minúscula na coluna e maiúscula na linha) não diferem entre si pelo Teste de Tukey a $5 \%$ de probabilidade.

As 3 cultivares testadas, Campos Gerais, Gol 600 e Estilo, apresentaram menor número de ovos do caruncho quando tratadas com o óleo de algodão, mostrando que esta substância apresentou algum efeito negativo no comportamento do inseto (Tabela 3).

Para o teste de vigor e de germinação apresentado na Tabela 4, nota-se que houve diferença significativa entre as cultivares testadas, sendo que a cultivar Gol 600 apresentou $0 \%$ de vigor e de germinação, diferindo das demais cultivares.

Tabela 4. Teste de vigor (\%) e teste de germinação (\%) das diferentes cultivares de feijão. Paraguaçu Paulista, 2017.

\begin{tabular}{ccc}
\hline Cultivares & Teste de Vigor (\%) & Teste de Germinação (\%) \\
\hline Campos gerais & $68 \mathrm{a}$ & $55,4 \mathrm{a}$ \\
Estilo & $54,6 \mathrm{a}$ & $61,8 \mathrm{a}$ \\
Gol 600 & $0,0 \mathrm{~b}$ & $0,0 \mathrm{~b}$ \\
\hline $\mathrm{F}$ & $35,86^{* *}$ & $113,96^{* *}$ \\
\hline $\mathrm{CV}(\%)$ & 46,54 & 25,77 \\
\hline
\end{tabular}

Médias seguidas pela mesma letra não diferem entre si pelo Teste de Tukey a $5 \%$ de probabilidade.

**: significativo a $1 \%$; CV (\%): Coeficiente de variação.

No entanto, nota-se que o tratamento das sementes com óleo não influenciou negativamente no vigor onde passa pela câmara de aceleração e na germinação das sementes das cultivares, pois não houve diferença significativa entre os tratamentos (Tabela 5).

Tabela 5. Teste de vigor (\%) e teste de germinação (\%) das cultivares sem óleo de algodão e com óleo de algodão. Paraguaçu Paulista, 2017.

\begin{tabular}{ccc}
\hline Tratamentos & Teste de Vigor (\%) & Teste de Germinação (\%) \\
\hline Sem óleo & $35 \mathrm{a}$ & $40,4 \mathrm{a}$ \\
Com óleo & $46,4 \mathrm{a}$ & $37,73 \mathrm{a}$ \\
\hline $\mathrm{F}$ & $2,53^{\mathrm{ns}}$ & $0,52^{\mathrm{ns}}$ \\
\hline CV (\%) & 46,54 & 25,77 \\
\hline
\end{tabular}

Médias seguidas pela mesma letra não diferem entre si pelo Teste de Tukey a $5 \%$ de probabilidade.

${ }^{\text {ns }}$ : não significativo CV (\%): coeficiente de variação. 


\section{DISCUSSÃO}

Estudos sobre o potencial das espécies de vegetais, visando obter óleos essenciais, para uso na agricultura, como inseticidas botânicos, vêm crescendo. Esses óleos devem ser utilizados como um método de controle eficaz, com redução dos custos, preservação do ambiente e dos alimentos da contaminação química, tornando-se prática adequada à agricultura sustentável (BRITO et al., 2006).

Carvalho, Lima e Alves (2011) observaram em trabalho realizado com genótipos de feijãocaupi a não preferência para alimentação do caruncho C. maculatus a alguns genótipos testados.

Os óleos vegetais de girassol e de soja, demonstraram ser eficientes como ovicida e/ou larvicida de carunchos em feijão, em trabalho realizado por Arruda e Batista (1998).

Provavelmente, os óleos vegetais apresentam algumas substâncias ovicidas e ou larvicidas, além do que, pode-se atribuir ao efeito físico causado por esses óleos, podendo estes impedir a aderência dos ovos do inseto à testa da semente (ARRUDA; BATISTA, 1998).

O Brasil, devido a riqueza e abundância de espécies vegetais, pode ser considerado um celeiro para a descoberta de efeitos inseticidas de espécies vegetais antes explorada para outros fins, mas que seus subprodutos podem ser aproveitados para o controle de pragas em diversas formas.

A não germinação das sementes Gol 600, possivelmente ocorreu em função de problemas sanitários da própria semente. Foi detectado nas sementes grande quantidade do microrganismo Aspergillus flavus, que é um dos principais fungos encontrados em armazenamento. Portanto, a deterioração das sementes provavelmente ocorreu em função do fungo e não devido a presença do óleo de algodão.

Assim, pode-se constatar que, os tratamentos com óleo vegetal de algodão em ambas as cultivares não alteraram o vigor e germinação das sementes; sendo, portanto, um tratamento viável ao produtor no processo de armazenamento.

\section{CONCLUSÃO}

O óleo vegetal de algodão demonstra ser eficiente na redução da oviposição e na emergência de adultos do caruncho $Z$. subfasciatus e não afeta a qualidade fisiológica da semente das cultivares testadas.

\section{REFERÊNCIAS}

AFONSO, S. M. E. Caracterização físico-química e atividade antioxidante de novas variedades de feijão (Phaseolus vulgaris L.). 2010. 52f. Dissertação (Mestre em Qualidade e Segurança Alimentar) - Escola Superior Agrária de Bragança - Instituto Politécnico, Bragança, 2010.

ARRUDA, F. P. de; BATISTA, J. de L. Efeito da luz, de óleos vegetais e de cultivares de caupi na infestação do caruncho (Callosobruchus maculatus (Fabr., 1775)) (Coleoptera: Bruchidae). Caatinga, Mossoró-RN, 11(1/2): 53-57, 1998.

BRASIL, Ministério da Agricultura e Reforma Agrária. Regras para análise de sementes. Brasilia, DF: SNDA/DNDV/CLAV, 2009. 365p.

BRITO, J. P.; BAPTISTUSSI, R. C.; FUNICHELLO, M.; OLIVEIRA, J. E. M.; BORTOLI, S. A. Efeito de óleos essenciais de Eucalyptus spp. Sobre Zabrotes subfaciatus (Bob.,183) (Coleoptera,Bruchidae) e Callosobruchus maculatus (Fab.1775) (Coleóptera: Bruchidae) em duas espécies de feijão, Boletim Sanidade Vegetal, n.32, p.573-580, 2006. 
CARVALHO, R. de O.; LIMA, A. C. S.; ALVES, J. M. A. Resistência de genótipos de feijão-caupi ao Callosobruchus maculatus (Fabr.) (Coleoptera: Bruchidae). Revista Agro@mbiente On-line, v. 5, n. 1, p. 50-56, jan-abril, 2011.

QUeIROGA, M. de F. C. de; GOMES, J. P.; ALMEIDA, F. de A. C.; PESSOA, E. B.; ALVES, N. M. C. Aplicação de óleo no controle de Zabrotes subfasciatus e na germinação de Phaseolus vulgaris. Rev. Bras. Eng. Agríc. ambient., vol.16, n.7, p.777-783, 2012. https://doi.org/10.1590/S1415$\underline{43662012000700011}$

SARI, L. T.; RIBEIRO-COSTA, C. S.; PEREIRA, P. R. V. da S. Aspectos biológicos de Zabrotes subfasciatus (Bohemann, 1833) (Coleoptera, Bruchidae) em Phaseolus vulgaris L., cv. Carioca (Fabaceae), sob condições de laboratório. Revista Brasileira de Entomologia 47(4): 621-624, 2003. https://doi.org/10.1590/S0085-56262003000400014 